\title{
Contiguous but dissimilar epithelial neoplasms of the urinary bladder
}

\author{
E. TAPP AND D. MORRISON \\ From the Departments of Pathology and Urology, Crumpsall Hospital, Manchester
}

SYNOPSIS An unusual tumour of the urinary bladder is described. It consists of two distinct nodules each with a quite different histological appearance, one being mucus-secreting adenocarcinoma, the other transitional cell carcinoma. Where the nodules are in contact there is little intermingling of the two histological patterns and it is suggested that the findings are probably due $\dot{\omega}$ to the collision of two separate neoplasms. Metaplastic changes are present in the bladder mucosa $\mathrm{N}$

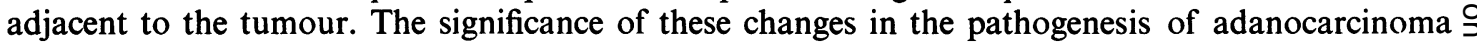
is discussed.

Mucus-secreting adenocarcinoma of the urinary bladder is a rare neoplasm comprising between 1 and $3 \%$ of the bladder neoplasms reported in two large series (Dean, Mostofi, Thomson, and Clark, 1954; Friedman and Ash, 1959). The latter authors consider that a misleadingly high incidence (up to $10 \%$ ) of glandular neoplasms given in other series is due to the inclusion in them of growths which are intrinsically papillary or transitional but have adenoid features. The tumour described below is unusual in that the transitional and glandular elements form two distinct malignant tumours which are only in contact over a small area.

\section{CASE REPORT}

A man aged 64 years came to the urological clinic at Crumpsall Hospital in March 1967 complaining of haematuria for one week. The only medical history of note was that of a gastric ulcer for which he had had a Billroth I gastrectomy combined with vagotomy in 1960 . Histological examination of the surgical specimen from this operation did not show any evidence of malignancy in the gastric ulcer.

At cystoscopy two days after first coming to the clinic a tumour described as being between 3 and $4 \mathrm{~cm}$ in diameter was seen to be arising from the mucosa on the left side of the dome of the bladder. A biopsy was taken for histological examination and reported as adenocarcinoma.

At operation the following week there was no evidence of extension of the tumour through the wall of the bladder and no sign of metastases in the pelvic or abdominal lymph nodes, or in the liver. In view of the biopsy report possible sites for a primary adenocarcinoma, particularly

Received for publication 7 September 1967. the intestines, were examined and found to be normal. $\vec{\varphi}$ A partial cystectomy, to include the tumour and a good $\mathscr{D}_{\infty}$ cuff of bladder, was performed. The patient made a good postoperative recovery and when last seen in the OutPatient Department, three months later, was free of urinary symptoms.

PATHOLOgICAL EXAMINATION The partial cystectomy $\mathbb{D}$ specimen is shown in Figure 1. The tumour consists of two fairly distinct nodules each of similar size together with a much smaller nodule which lies above the other two in the photograph. The two main nodules are separated by a narrow cleft. The nodule on the right is

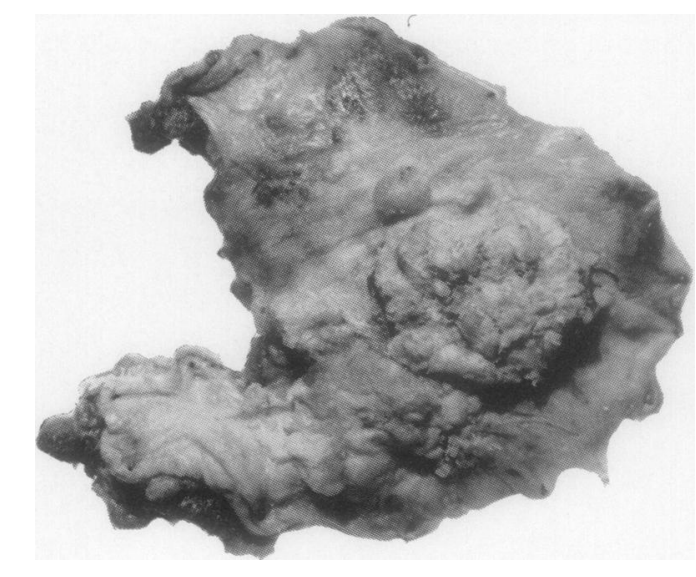

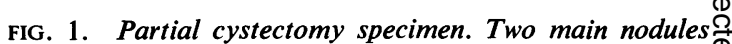
together with a much smaller nodule can be seen. The large nodule on the right is rounded but the one on the leftত is more irregular in shape. 
rounded, $2.5 \mathrm{~cm}$ in diameter, and raised to $1.5 \mathrm{~cm}$ above the normal mucosa. Its surface is roughened and occasional papillary projections are present. The nodule on the left is more irregular in shape measuring $3 \mathrm{~cm}$ in its maximum dimension and rising to $1 \mathrm{~cm}$ above the normal mucosa. The surface of this part of the tumour is fairly smooth and is devoid of papillary projections.

The histological appearance of the tumour in each nodule is quite different. The nodule on the right is composed of solid cords of transitional cells with relatively little connective tissue stroma. A moderate amount of pleomorphism is present in some areas and occasional mitoses are seen. There is no evidence of glandular differentiation in this part of the lesion. The muscle at the base of the tumour is invaded but not beyond the inner one third of the bladder wall.

The nodule on the left has a glandular pattern with papillary and acinar structures lined by a single or by multiple layers of columnar epithelium. Mucin is demonstrable both in the tumour cells and as extracellular pools. No evidence of a transitional cell pattern is present in this nodule. Invasion of the bladder wall by glandular acini is seen but this is rather more superficial than in the transitional cell nodule. Where the nodules are in contact the junction between the two patterns of neoplasm is for the most part quite sharp, although there is slight intermingling in some areas (Fig. 2).
The bladder mucosa surrounding most of the tumour is normal but that adjacent to the nodule on the left shows a number of abnormalities. Nests of Von Brunn are present and some of these have undergone central necrosis forming areas of cystitis cystica. Liquefactive necrosis is also seen in the surface epithelium (Fig. 3). Metaplasia to a mucin-secreting glandular epithelium is present and in a number of places this epithelium shows marked cellular abnormalities (Fig. 4).

\section{DISCUSSION}

From the description given above it is clear that there are two histologically distinct areas of neoplasm in the bladder, one a papillary transitional cell carcinoma and the other a mucus-secreting adenocarcinoma. Areas of glandular differentiation are occasionally seen in transitional cell neoplasms (Friedman and Ash, 1959) and this is said to occur more commonly in invading papillary neoplasms than in sessile lesions (Ash, 1940). However, glandular metaplasia has also been described on the surface of a poorly differentiated transitional cell carcinoma (Kittredge, Henthorne, and Whitehead, 1947). In addition Mostofi, Thomson, and

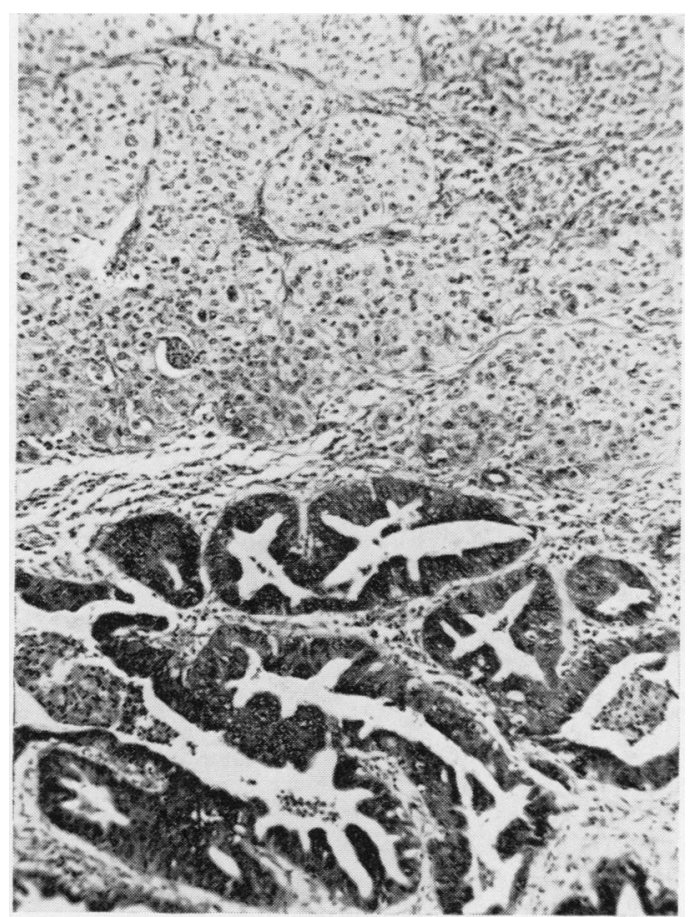

FIG. 2.

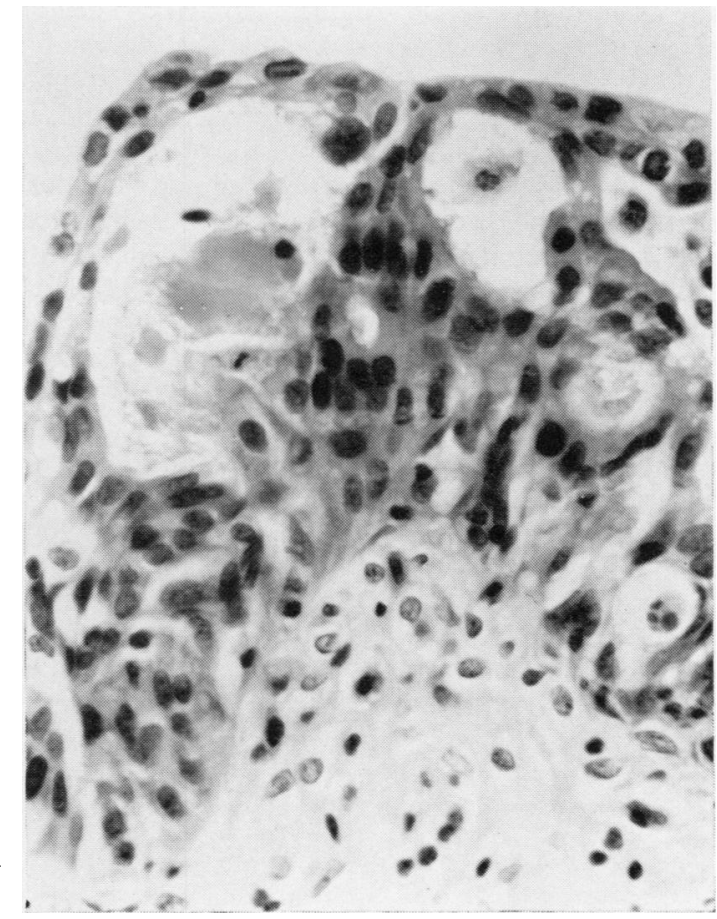

FIG. 3.

FIG. 2. The junction between the two patterns of tumour is quite sharp in this area. Haematoxylin and eosin $\times 90$. FIG. 3. Liquefactive necrosis of groups of cells in the surface epithelium has resulted in small cystic areas. Haematoxylin and eosin $\times 400$. 


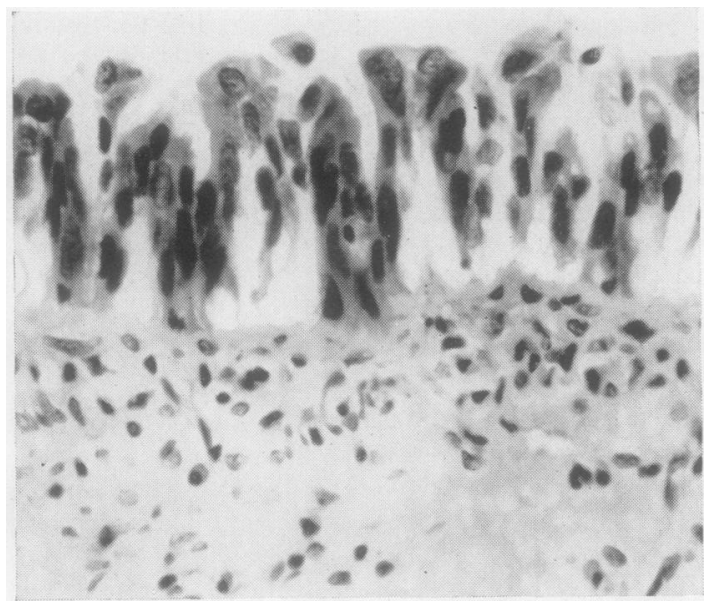

FIG. 4. The surface epithelium in this area has lost its typical transitional cell structure and the cytoplasm of many of the cells is vacuolated. The latter are mucin positive in appropriately stained sections. Haematoxylin and eosin $\times 400$.

Dean (1955) found small areas of transitional cell carcinoma in six of their $\mathbf{4 4}$ cases of mucus-secreting adenocarcinoma of the bladder. Both these groups of neoplasms, whether predominantly transitional cell or glandular carcinomas, consist of intimate mixtures of the two patterns. On the other hand, in the tumour which is the subject of the present report, the way in which the transitional cell and glandular elements form the distinct neoplasms of comparable size indicates that here we are probably dealing with the collision of two separate neoplasms. Although there are reports in the literature of the coexistence of carcinoma and sarcoma in the bladder (Hejtmancik and Klatt, 1960), we have been unable to find a description of the occurrence of distinct malignant neoplasms with quite different histological appearances as in the present instance.

No evidence can be put forward on the aetiology of the neoplasms in this man. As far as can be ascertained he had not been exposed to any carcinogenic chemicals. A metastatic origin for the adenocarcinoma was considered, especially as he was known to have had a gastric ulcer. However, as we have seen, there was no evidence of malignancy in the gastrectomy specimen. In addition the intestines were examined carefully at operation and no sign of a primary neoplasm was detected. The $\frac{0}{5}$ position of the adenocarcinoma on the mucosal surface of the bladder is also against its being $\overrightarrow{\bar{N}}$ metastatic (Mostofi et al., 1955). Assuming, therefore, that the adenocarcinoma is a primary one in the bladder there are a number of possibilities to be considered. An origin from urachal remnants can be dismissed as the growth arose away from the apex of the bladder and we can add nothing to the $\infty$ dysontogenic theory in general, the case for which $\overrightarrow{0}$ has been argued strongly by Friedman and Ash $\overrightarrow{\vec{\omega}}$ (1959). On the other hand the metaplastic changes $\omega_{0}$ seen in the bladder mucosa adjacent to the tumour may be of aetiological importance. The association of cystitis cystica and cystitis glandularis with adenocarcinoma of the bladder has been described by Patch and Pritchard (1947), Immergut and Cottler $\omega_{N}^{\omega}$ (1950), Wheeler and Hill (1954), Shaw, Gislason, $\circ$ and Imbriglia (1958) and Kittredge, Collet, and Morgan (1964), and cystitis glandularis was con- $\vec{z}$ sidered to be a premalignant condition by the latter two groups of authors. Moreover the cytological abnormalities seen in the metaplastic areas in the $\mathscr{\circ}$ present case are similar to those described by Shaw et al. (1958). These workers took serial biopsies from the bladder of one patient over a period of five years and were able to trace the transformation of cystitis glandularis through a stage in which $ٌ$

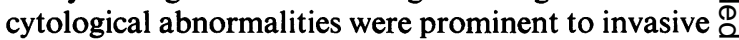
adenocarcinoma.

We wish to thank Mr D. S. Poole-Wilson for permission to publish the clinical details of this case. The photographs are the work of Miss Jean Perry of the Department of Medical Illustration.

\section{REFERENCES}

Ash, J. E. (1940). J. Urol. (Baltimore), 44, 135.

Dean, A. L., Mostofi, F. K., Thomson, R. V., and Clark, M. L. (1954). Ibid., 71, 571 .

Friedman, N. B., and Ash, J. E. (1959). Tumors of the Urinary Bladder (Atlas of Tumor Pathology, Sect. VIII, Fasc. 31a), p. 50. I Armed Forces Inst. Path., Washington, D.C.

Hejtmancik, J. H., and Klatt, W. W. (1960). J. Urol. (Baltimore). $84,320$.

Immergut, S., and Cottler, Z. R. (1950). Urol. cutan. Rev., 54, 531. G

Kittredge, W. E., Henthorne, J. C., and Whitehead, M. (1947). J. Urol. N (Baltimore), 58, 282.

, Collet, A. J., and Morgan, C., Jr. (1964). Ibid., 91, 145.
Mostofi, F. K., Thomson, R. V., and Dean, A. L., Jr. (1955). Cancer (Philad.), 8, 741.

Patch, F. S., and Pritchard, J. E. (1947). J. Urol. (Baltimore), 57, 126.0

Shaw, J. L., Gislason, G. J., and Imbriglia, J. E. (1958). Ibid., 79, 815.

Wheeler, J. D., and Hill, W. T. (1954). Cancer (Philad.), 7, 119. 